\title{
Study of the Determinants of Food Diversification Among Pregnant Women in the Dakar Region in 2017 - Senegal
}

\author{
Maty Diagne Camara ${ }^{1}$, Oumar Bassoum ${ }^{2}$, Cheikh Tacko Diop ${ }^{3}$, Thérésa Foucko Moko ${ }^{1}$, \\ Mamadou Makhtar Mbacké Leye ${ }^{2}$, Mayacine Ndiongue², Jean Augustin Diégane Tine², \\ Khadim Niang ${ }^{2}$, Adama Faye ${ }^{2}$ \\ ${ }^{1}$ Department of Preventive Medicine and Public Health, Faculty of Medicine, Pharmacy and Odontology, Institute of Health and \\ Development, Cheikh Anta Diop University, Dakar, Senegal \\ ${ }^{2}$ Department of Preventive Medicine and Public Health, Faculty of Medicine, Pharmacy and Odontology, Cheikh Anta Diop University, \\ Dakar, Senegal \\ ${ }^{3}$ Department of Community Health, Bambey University, Diourbel, Senegal
}

Email address:

matydiagnecamara@gmail.com (M. D. Camara), matydiagne@yahoo.com (M. D. Camara)

\section{To cite this article:}

Maty Diagne Camara, Oumar Bassoum, Cheikh Tacko Diop, Thérésa Foucko Moko, Mamadou Makhtar Mbacké Leye, Mayacine Ndiongue, Jean Augustin Diégane Tine, Khadim Niang, Adama Faye. Study of the Determinants of Food Diversification Among Pregnant Women in the Dakar Region in 2017 - Senegal. Central African Journal of Public Health. Vol. 6, No. 1, 2020, pp. 42-47.

doi: 10.11648/j.cajph.20200601.17

Received: January 2, 2020; Accepted: January 16, 2020; Published: January 21, 2020

\begin{abstract}
As part of the prevention of nutritional deficiencies in pregnant women, the objective of the study is to identify the determinants of food diversity in pregnant women in the Dakar region. Cross-sectional survey in a three-stage cluster design. Two health districts in the Dakar region were randomly selected from urban and peri-urban areas. All pregnant women in the health centers were surveyed until the sample size was obtained. The data collected are socio-demographic, economic, pregnancy-related factors, practices and knowledge about nutrition and food groups consumed the day before the survey. A bivariate analysis was done using R software. Relevant covariables were included in the linear regression analysis to identify the factors associated with food diversity. A total of 300 pregnant women were surveyed in two different health districts, one in urban and one in peri-urban areas. The average age of women varies between 16 and 45 years with an average of 28.02 years, with a standard deviation of 5.4 years. The average dietary diversity score was 5.47 , with a standard deviation of 1.24 . Women aged 16 to 19 had the highest food diversity score of $6.12( \pm 1.54)$ with a $\beta=-1.14[-1.8 ;-0.48]$. This score is lower in urban areas (CS Gaspard Camara) 5.28 than in peri-urban areas (CS Mbao) 5.67, $\beta=0.39$ [0.12; 0.67]. Women with three or more children had a more diversified diet with $\beta=0.56[0.12 ; 0.67]$. The income of the head of household is decisive for the diversification of pregnant women with $\beta=0.79[0.24 ; 1.35]$. The dietary knowledge and practices related to dietary diversity of pregnant women was the consumption of mineral water $\beta=0.27[0.001 ; 0.5]$.
\end{abstract}

Keywords: Food Diversification, Pregnant Women, Dakar

\section{Introduction}

Food diversity is an essential concept in understanding malnutrition, whether excessive or default, in all age groups, especially in developing countries. It can lead to a healthy and balanced diet, especially for pregnant women, which is very crucial and decisive for the survival and good health of the fetus and mother. Lack of food diversity is particularly a serious problem among poor people in developing countries whose daily diet is generally based on a starch source (cereals, tubers) with one or two additional components. This type of diet tends to be poor in several micronutrients and the micronutrients it contains often have low bioavailability. Food diversity determines the number of different food groups consumed by an individual or household over a given period. At the international level, dietary guidelines recommend $[1,2]$ consuming a sufficient variety of foods, which is supposed to ensure adequate 
intakes of essential nutrients for good health. In the 1950s, these recommendations were based on protein-rich diets, then energy-rich diets (kilocalories), and more recently, efforts have been made to eliminate micronutrient deficiencies through supplementation and food fortification [3]. Although agricultural production is sufficient for all humanity, 840 million people do not have enough to eat in the world [4]. In developing countries, household living conditions, often very precarious, have consequences on the nutritional status of pregnant women and infants, on the state of health at birth and on the psychosocial environment. Many disadvantaged pregnant women have poor nutrition and poor nutritional status. In these countries, experiments in measuring food diversity are much limited and mainly concern the feeding of young children. The few studies [5, 6] carried out in these countries have highlighted the value of simple indices measuring diversity through the number of food groups or sub-groups consumed over a given period of time.

However, they also showed significant differences between the methods used to construct these indices in terms of the nature and number of food groups and the reference period used. An effort to harmonize these indices has been initiated at the international level, in particular with the establishment of workshops, expert groups, discussions and reports on the theme of measuring food diversity [7, 8]. Despite the lack of homogeneity found, they agreed that the food diversity score was a very good tool to help measure the overall quality of diets in both industrialized and developing countries [9]. The nutritional status of women at the time of pregnancy and during pregnancy can have a significant influence on the health of the fetus, infant and mother [10] Studies have shown the link between poor quality nutrition in pregnant women and the occurrence of low birth weight (LBW).

In many developing countries, common maternal undernutrition results in insufficient fetal development and an increased risk of pregnancy complications. Undernutrition in mothers and children is responsible for more than $10 \%$ of the global burden of disease [11]. In Senegal, according to the 2010 Multiple Indicator Cluster Survey [12], stunting, one of the three forms of malnutrition that exist, was estimated at $27 \%$. Senegal experienced a major food crisis in 2012 [13], characterized by a significant decline in agricultural production of all cultivated species. This decrease thus puts some localities in a difficult food situation in the country. This has influenced household eating habits and altered nutritional quality. Nevertheless, the factors are often environmental, behavioural, socio-cultural and economic $[14,15]$. Non-diversification of food in pregnant women impacts child survival and health, which becomes a breeding ground for chronic malnutrition and is characterized by growth retardation, morbidity, mortality risks, cognitive and motor development disorders, low physical and intellectual performance [16]. Thus, the objective of this work is to identify the determinants of food diversity among pregnant women in the Dakar region.

\section{Study Framework}

Dakar, the capital of Senegal, is located in the far west in the Cape Verde peninsula on the Atlantic Ocean and covers an area of $550 \mathrm{~km}^{2}$, or $0.28 \%$ of the national territory. It is administratively organized into four (04) departments: Dakar, Pikine, Guédiawaye and Rufisque. The population of Dakar is 3,137,196 inhabitants, almost a quarter of the population of Senegal with an urbanization rate of $96 \%$. The population of Dakar is very young, with $44.5 \%$ of the population under 20 years of age [17].

Senegal's health system is pyramidal at three levels. The lowest level, the peripheral level which corresponds to the health district, the second level corresponds to the medical region and the third level is the central level (MSAS). The medical region is the coordinating structure and has 11 health departments.

\section{Method}

\subsection{Type of Study}

Cross-sectional study taking place from 1 November to 15 December 2018.

\subsection{Study Population}

Pregnant women in the Gaspard Camara and Sicap Mbao health districts of the Dakar region. Were included all pregnant women who came for their prenatal visit on the day of the survey and were excluded all women with a medical surgical history that could influence diet diversification such as: Diabetes, Dyslipidemia, Gastric surgery and all women included but who have undergone a voluntary or contextual dietary modification (e. g. fasting, participation in a family ceremony, etc.).

\subsection{Sampling Method}

Was based on a three-stage stratified survey. Two health districts in the Dakar region were randomly selected (one in urban areas: the central district and the other in peri-urban areas: the Mbao district); then, for each health district, we chose the reference health center: Gaspard Camara health center and the Sicap Mbao health center. Finally, in each center, we surveyed all the pregnant women we found in prenatal consultations until we obtained our desired sample size

The sample size was calculated using Schwartz's formula $\mathrm{n}=, 292$ women, and we rounded to 300 pregnant women.

\subsection{Data Collection}

The data were collected using a questionnaire that was administered to pregnant women next to the antenatal consultation room after the antenatal consultation. An information and consent letter was presented to them to obtain their free and informed consent before the questionnaire was administered.

The Questionnaire was divided into five parts:

1. Sociodemographic characteristics;

2. Professional and economic characteristics;

3. Pregnancy characteristics; 
4. Food knowledge and practices;

Food diversity measurement: any food and beverage consumed from morning to evening during the 24 hours preceding the survey. The number of food groups consumed by women on the eve of the survey is eleven: cereals, roots and tubers, legumes, nuts and seeds, dairy products, meat products, offal, eggs, dark green leafy vegetables, vitamin Arich fruits and vegetables, other fruits and vegetables. Food diversity was appreciated through what the woman ate and drank at breakfast, lunch, dinner including snacks inside or outside the household. After she quoted everything she had consumed, an open recall was made. For the open recall, the investigator had to quote the subfoods of each group by asking the woman if and when she had consumed them per day for the seven days.

Diet was considered poorly diversified when the woman consumed less than four food groups, it was moderately diversified when the woman consumed between four and six food groups, and adequate when she consumed more than six food groups

\subsection{Analysis}

The descriptive analysis of the qualitative variables was carried out with the frequency and $95 \%$ confidence interval and the quantitative variables with the mean being its standard deviation.

Bivariate analysis: the comparison of averages was made by the Student test and the ANOVA according to the application conditions with a significance level of $5 \%$. This analysis allowed us to sort the variables with a p-value of less than 0.20 for modelling.

Multivariate linear regression was conducted to determine factors associated with dietary diversity in pregnant women by controlling for potential confounding factors. All variables with a p-value of less than 0.20 [18] were included in the multiple linear regression analysis to investigate the relationships of factors associated with dietary diversity. The nested, top-down step model method was used to select the final model by removing at each level the variable that had the greatest $\mathrm{p}$-value in the model. The anova function was used for the comparison between two nested models after removing a variable, the significance threshold of the test was set at $5 \%$.

\section{Results}

\subsection{Descriptive Analysis}

A total of 300 pregnant women were surveyed. (See Table 1). Women's age varied between 16 and 45 years with an average of 28.02 years, a standard deviation of 5.4 years and a median of 28 years. The majority $(94.7 \%)$ of women were between 19 - 45 years of age. Seventy-eight percent (78\%) of women were married monogamous, followed by $17 \%$ who were in a polygamous marriage. The dominant ethnic group was represented by the wolofs $39 \%$. More than half $(56 \%)$ stayed with their mother or mother-in-law, compared to $44 \%$.
More than $3 / 4$ lived with their husbands (84.33\%). The average number of children per woman was 1.47 with a standard deviation of 1.29. Fourteen percent of the women had a number of children between zero and three and $7 \%$. The average number of people living in the household was 5.16 with a standard deviation of 1.77 .

About $83 \%$ of the women were educated and the level of education was distributed as follows: $30.65 \%$ primary level, $40.32 \%$ secondary level and $29.03 \%$ higher level. Only $9 \%$ of pregnant women had a paid job with $33.33 \%$ secretaries and $22.22 \%$ working in the health sector.

More than half of the women $(52.33 \%)$ had an income with $59.87 \%$ of income less than or equal to 50,000 CFA francs, and 40.13 had incomes above 50,000 CFA francs. The majority of women $90.33 \%$ did not receive a social security grant.

The majority of husbands had a profession, i.e. $97.9 \%$ with $81.95 \%$ income above CFAF 50,000

Table 1. Distribution of women by pregnancy characteristics, knowledge of dietary practices, cooking methods of foods consumed and food diversity score.

\begin{tabular}{|c|c|c|c|}
\hline & $\begin{array}{l}\text { Terms and } \\
\text { conditions }\end{array}$ & $\begin{array}{l}\text { Relative } \\
\text { number }\end{array}$ & $\begin{array}{l}\text { Relative } \\
\text { number }\end{array}$ \\
\hline \multicolumn{4}{|c|}{ Pregnancy Characteristics $(\mathrm{n}=300)$} \\
\hline \multirow{3}{*}{ Age of pregnancy } & 1st quarter & 50 & 16,67 \\
\hline & 2nd quarter & 138 & 46 \\
\hline & 3rd quarter & 112 & 37,33 \\
\hline \multirow{2}{*}{ Folic Acid Iron Intake } & Yes & 287 & 95,67 \\
\hline & No & 13 & 4,33 \\
\hline \multirow{2}{*}{ Number CPN } & $0-3$ & 229 & 76,3 \\
\hline & $4-7$ & 71 & 23,7 \\
\hline \multicolumn{4}{|c|}{ Food Practical Knowledge $(n=300)$} \\
\hline \multirow{2}{*}{ Food diversification } & Yes & 300 & 100 \\
\hline & No & 0 & 0 \\
\hline \multirow{2}{*}{$\begin{array}{l}\text { Compliance with hygiene } \\
\text { conditions }\end{array}$} & Yes & 298 & 99,33 \\
\hline & No & 2 & 0,68 \\
\hline \multirow{2}{*}{ Adequate food storage } & Yes & 236 & 78,67 \\
\hline & No & 64 & 21,33 \\
\hline \multicolumn{4}{|c|}{ Cooking methods for food consumed } \\
\hline \multirow{2}{*}{ Broth } & Yes & 295 & 98,33 \\
\hline & No & 5 & 1,67 \\
\hline \multirow{2}{*}{ Steam cooking } & Yes & 20 & 6,67 \\
\hline & No & 280 & 93,33 \\
\hline \multirow{2}{*}{ Cooking in oil Broth } & Yes & 295 & 98,33 \\
\hline & No & 5 & 1,67 \\
\hline \multicolumn{4}{|l|}{ Hygiene practices used } \\
\hline \multirow{2}{*}{ Tap water consumption } & Yes & 298 & 99,33 \\
\hline & No & 2 & 0,67 \\
\hline \multirow{2}{*}{ Mineral water consumption } & Yes & 155 & 51,67 \\
\hline & No & 145 & 48,33 \\
\hline \multirow{2}{*}{ Rainwater consumption } & Yes & 5 & 1,67 \\
\hline & No & 295 & 98,33 \\
\hline \multirow{2}{*}{ Hand washing } & Yes & 298 & 99,33 \\
\hline & No & 2 & 0,67 \\
\hline \multirow{2}{*}{ Hand washing after washing } & Yes & 299 & 99,67 \\
\hline & No & 1 & 0,33 \\
\hline \multirow{2}{*}{$\begin{array}{l}\text { Food washing before } \\
\text { consumption }\end{array}$} & Yes & 299 & 99,67 \\
\hline & No & 1 & 0,33 \\
\hline Mean & Median & \multicolumn{2}{|c|}{ Standard Deviation } \\
\hline \multicolumn{4}{|c|}{ Women's 24-hour Dietary Diversity core (WDDS) } \\
\hline WDDS $\quad 5,47$ & 5 & 1,24 & \\
\hline
\end{tabular}




\subsection{Bivariate Analysis}

The analysis was done with the average food diversity score from the 24-hour recall. With regard to sociodemographic characteristics, a statistically significant difference was observed $(\mathrm{p}=0.03)$ between the average food diversity score and the age of women. It is higher among younger women aged 16 to 19 (6.12 [3.10 - 9.13]) compared to pregnant women aged 20 to 45 (5.44, [3.06 - 7.81]).

Also according to the location of pregnancy follow-up, a statistically significant difference was observed with $\mathrm{p}=0.005$, between the mean food diversity score for women who were followed at Gaspard CAMARA (SMDAF=5.28 [2.88 - 7.67]) compared to those followed at Khadim Rassoul Health Centre (SMDAF) 5.67 [3.27- 8.06]) (see Table 2).

Table 2. Link between the average food diversity score among pregnant women in the Dakar region and socio-demographic characteristics, professional characteristics, pregnancy characteristics, hygiene practices used.

\begin{tabular}{|c|c|c|c|c|}
\hline & Termsand conditions & 24H WDDS & Interval of $95 \%$ confidence & P value \\
\hline \multicolumn{5}{|l|}{ Socio-demographic characteristics } \\
\hline \multirow{2}{*}{ Age } & $16-19$ years & 6,12 & {$[3,10-9,13]$} & \multirow{2}{*}{0,03} \\
\hline & $20-45$ years & 5,44 & {$[3,06-7,81]$} & \\
\hline \multirow{2}{*}{ Marital status } & Married women & 5,5 & {$[3,08-7,91]$} & \multirow{2}{*}{0,14} \\
\hline & Unmarried & 5 & {$[2,56-7,43]$} & \\
\hline \multirow{2}{*}{ Number of children } & {$[0-3]$} & 5,44 & {$[3,02-7,85]$} & \multirow{2}{*}{0,1} \\
\hline & [3-7] & 5,9 & {$[3,35-8,44]$} & \\
\hline \multirow{2}{*}{ Number of people in the household } & {$[0-10]$} & 5,48 & {$[3,04-7,91]$} & \multirow{2}{*}{0,2} \\
\hline & [10-11] & 4 & {$[3,98-4,01]$} & \\
\hline \multicolumn{5}{|l|}{ Professional characteristics } \\
\hline \multirow{5}{*}{ Type of profession pregnant woman } & Trader & 5,18 & {$[3,71-6,65]$} & \multirow{5}{*}{0,2} \\
\hline & Secretary & 5,4 & {$[3,10-7,69]$} & \\
\hline & Health Agent & 5,66 & {$[2,99-8,32]$} & \\
\hline & Teacher & 6 & {$[5,98-6,01]$} & \\
\hline & Student & 7,5 & {$[6,12-8,87]$} & \\
\hline \multirow{2}{*}{ Husband's income } & Yes & 5,51 & {$[3,07-7,94]$} & \multirow{2}{*}{0,3} \\
\hline & No & 5,11 & {$[3,3-6,91]$} & \\
\hline \multirow{2}{*}{ Estimate of the husband's income } & More than $50.000 \mathrm{fcfa}$ & 5,53 & {$[3,25-7,8]$} & \multirow{2}{*}{0,18} \\
\hline & Less than or equal to $50,000 \mathrm{f}$ & 5,42 & {$[2,34-8,49]$} & \\
\hline \multicolumn{5}{|l|}{ Pregnancy characteristics } \\
\hline \multirow{2}{*}{ Number of NOCs } & $\leq$ à 3 & 5,41 & {$[3,11-7,7]$} & \multirow{2}{*}{0.12} \\
\hline & $>$ à 3 & 5,67 & {$[2,88-8,45]$} & \\
\hline \multirow{2}{*}{ Place of pregnancy follow-up } & Gaspard Camara & 5,28 & {$[2,88-7,67]$} & \multirow{2}{*}{0,005} \\
\hline & Khadim Rassoul & 5,67 & {$[3,27-8,06]$} & \\
\hline \multicolumn{5}{|l|}{ Hygiene practices used } \\
\hline \multirow{2}{*}{$\begin{array}{l}\text { Consumption of } \\
\text { mineral water }\end{array}$} & Yes & 5,57 & {$[3,45-7,68]$} & \multirow{2}{*}{0.15} \\
\hline & No & 5,37 & {$[2,66-8,07]$} & \\
\hline \multirow{2}{*}{ Rainwater consumption } & Yes & 4,8 & {$[2,68-6,91]$} & \multirow{2}{*}{0.21} \\
\hline & No & 5,48 & {$[3,04-7,91]$} & \\
\hline
\end{tabular}

\subsection{Multivariate Analysis}

The multivariate linear regression model investigated factors associated with dietary diversity among pregnant women in the Dakar region. These factors are age $-1.14[-1.8 ;-0.48]$ with $\mathrm{p}=0.0007$, place of follow-up $0.39[0.12 ; 0.67]$ with $\mathrm{p}=0.004$, number of children $0.56[0.25 ; 1.1]$ with $\mathrm{p}=0.04$ the consumption of mineral water $0.27[0.001 ; 0.5] \mathrm{p}=0.048$ and finally the husband's income $0.79[0.24 ; 1.35]$ with $\mathrm{p}=0.005$. (See Table 3 ).

Table 3. Factors associated with food diversity (by multiple linear regression).

\begin{tabular}{|c|c|c|c|c|}
\hline Factors to consider & Partners Modalities & Coefficient $\beta$ adjusted & Interval of $95 \%$ confidence & P-value \\
\hline \multicolumn{5}{|l|}{ Age } \\
\hline $16-19$ years & & Réf. & & \\
\hline $20-45$ years & & $-1,14$ & {$[-1,8 ;-0,48]$} & 0,0007 \\
\hline \multicolumn{5}{|c|}{ Place of pregnancy follow-up } \\
\hline CS G. Camara & & Réf & & \\
\hline CS de Sicap Mbao & & 0,39 & {$[0,12 ; 0,67]$} & 0,004 \\
\hline \multicolumn{5}{|l|}{ Number of children } \\
\hline$[0-3]$ & & Réf. & & \\
\hline$[3-7]$ & & 0,56 & {$[0,25 ; 1,1]$} & 0,04 \\
\hline
\end{tabular}




\begin{tabular}{|c|c|c|c|c|}
\hline Factors to consider & Partners Modalities & Coefficient $\beta$ adjusted & Interval of $95 \%$ confidence & P-value \\
\hline \multicolumn{5}{|c|}{ Mineral water consumption } \\
\hline No & & Réf. & & 0,048 \\
\hline Yes & & 0,27 & {$[0,001 ; 0,5]$} & \\
\hline \multicolumn{5}{|l|}{ Husband's income } \\
\hline No & & Réf. & & 0,005 \\
\hline Yes & & 0,79 & {$[0,24 ; 1,35]$} & \\
\hline
\end{tabular}

\section{Discussion}

Several authors $[8,19,20]$ consider that the use of diversity indices based on food groups is simpler, more informative about the actual quality of diets and even more effective in predicting the nutritional adequacy of diets. The calculation of the diversity score makes it possible to make a decision in case of a crisis situation and to make a good targeting.

In Dakar, the average dietary diversity among pregnant women is 5.47, similar to the results of Mathilde Savy [21] who found an average diversity equal to 5.1 for a sample of 691 mothers of children in Ouagadougou. On the other hand, Elodie Becquey [22] had found an average diversity equal to 4.2. Taking into account the classification, we can say that the dietary diversity among pregnant women in the Dakar region is average. This would be explained by the ability of the national dish "thiéboudiène" alone to contain three to four food groups. Although women diversify their diet through more or less filled national dishes, we have found that their diet is not varied because they consume the same diversified dishes without varying them.

Our study [23] revealed that the food diversity score was better in the $16-19$ age group with a $\beta=1.14[0.48 ; 1.8]$. This may be due to the fact that a primigestist pays more attention to her pregnancy and diet. This also makes sense since at these ages they are newly married with fewer children, and the absence of burdens would justify this ability to feed themselves without difficulty. Marital status had no effect on the quality of diet in pregnant women. However, a study conducted in France on the diet of elderly people shows that elderly people in couples or cohabitation had a more diversified diet than those who were single.

Ethnicity does not influence food diversification in Dakar due to ethnic diversity. However, a study carried out in Mali by action against hunger [24] on Food Diversity and Food Diversification in the Banamba Circle (Padaba) showed that the Peulhs had a much higher food diversity than other ethnic groups.

The average food diversity in urban areas was lower at 5.28 than in peri-urban areas at $5.67, \beta=0.39$ [0.12;0.67]. Unlike the study done in Burkina Faso by Savy [25], the average food diversity score is 4.9 in urban areas compared to 3.4 in rural areas. This could be explained by the fact that in urban and peri-urban areas, markets are better and more easily supplied than in rural areas where access to food is more difficult.

Women with three or more children had a more diversified diet than those with fewer than three children $\beta=0.56[0.12$;
$0.67]$. Indeed, women with more than 3 children have a better income than others ( $\mathrm{OR}=3.13[1.1 ;-8.78])$.

The income of the head of household had an influence on the quality of the diet with a food diversity score $\beta=0.79$ $[0.24 ; 1.35]$. A study on the relationship between production diversity, agricultural income and food diversity in rural Burkina Faso [26] found that women receiving a cash transfer from the farm or household head had better food diversity in all seasons. The location of pregnancy follow-up is a factor related to good food diversity $\beta=0.39[0.12 ; 0.67]$. Indeed, women in peri-urban areas had a better diversity than those followed in urban areas. This could be explained by the fact that peri-urban providers did much more nutrition education during prenatal consultations.

The only knowledge and practices statistically related to dietary diversity among pregnant women was the consumption of mineral water $\beta=0.27[0.001 ; 0.5]$. Women who consumed mineral water had a higher average dietary diversity score of 5.57 compared to those who did not. This could be explained by the fact that their socio-economic level is better than that of those who consumed water from wells, rains and rivers, and from the tap.

Activities oriented towards the production of food goods had no effect on the food diversity score. In accordance with the results found by Lourme Ruiz and his collaborators [25] who concluded that "women's control of resources seems to be a better guarantee of the quality of their food than the level of agricultural production on the farm". This was found by a study conducted in Sikasso, Mali by Dury [27] on the persistence of malnutrition in children despite high agricultural production.

\section{Conclusion}

The diet of pregnant women has not been the subject of much research in Senegal. This study has provided us with data on dietary diversity among pregnant women in the Dakar region, but better understand the factors associated with dietary diversity in pregnant women. Although the financial means are not favourable enough for women in the Dakar region, we were able to see that the diet was moderately diversified. However, in order to improve this situation it is important to develop national dietary recommendations and to build national food composition tables to allow populations to have clear messages for good food choice to improve their dietary diversification. Capacity building of midwives on nutrition and feeding of pregnant women is also needed to enable them to provide good nutrition education to pregnant women. 


\section{References}

[1] U.S. Department of Agriculture Human Nutrition Information Service. Food Guide Pyramid: A guide to daily food choices., DC: US Departments of Agriculture and Health and Human Resources. Home and Garden Bulletin No. 249. 1992.

[2] Joint F, World Health Organization. Preparation and use of food-based dietary guidelines. 1998.

[3] Torres AC. Revue Bibliographique des outils pour la mesure des relations entre agrobiodiversité et nutrition. 2013.

[4] OXFAM. The World Food Situation. Jan 2014; 2.

[5] Tarini A, Bakari S, Delisle H. The overall nutritional quality of the diet is reflected in the growth of Nigerian children. Santé Montrouge Fr. 1999; 9 (1): 23-31.

[6] Leroy JL, Habicht J-P, Ruel MT, Simler KR, Dittoh S. Household dietary diversity is associated with child dietary diversity and nutritional status. 2012.

[7] FAO/WHO/IFPRI. Workshop on Dietary Diversity and Dietary Quality. oct 2004; 11-3.

[8] Swindale A, Bilinsky P. Household Dietary Diversity Score (HDDS) for Measurement of Household Food Access: Indicator Guide. Washington, DC: Food and Nutrition Technical Assistance Project, Academy for Educational Development. 2005.

[9] Rush D. Nutrition and maternal mortality in the developing world. Am J Clin Nutr. 2000; 72 (1): 212s-240s.

[10] Bhutta ZA, Das JK, Rizvi A, Gaffey MF, Walker N, Horton S, et al. Evidence-based interventions for improvement of maternal and child nutrition: what can be done and at what cost? The lancet. 2013; 382 (9890): 452-77.

[11] WHO report Malnutrition: the challenges. [Cited 5 July 2017]; Available at: http://www.who.int/nutrition/challenges/fr/)

[12] ANSD, Demographic and Health Surveys-DHS, CRDH): Enquête Démographique et de Santé à Indicateurs Multiples du Sénégal octobre 2010 à avril 2011 (EDS-MICS 201011).

[13] Executive Secretariat of the National Food Security Council. Final report: Surveillance of food security, nutrition and household livelihoods: 2nd sentinel site survey. Oct 2016, P 17.

[14] Mboumba A. Factors explaining malnutrition among children under five in Gabon. 2009.

[15] FAO. The State of Food Insecurity in the World, 2004: Monitoring Progress towards the World Food Summit and Millennium Development Goals, FAO, Rome, 2004, 208 p.

[16] S. Padonou. Risk factors and consequences on growth from birth to 18 months of life in Beninese newborns. Thesis Accessed 28.08.2017. P65. https://tel.archives- open.fr/tel01127580/document.

[17] National Agency for Statistics and Demography. Regional economic and social situation 2013. Apr 2015; 18-9.

[18] M. Tenenhaus, "Statistics: Methods for describing, explaining and predicting", Dunod, 2007.

[19] Hatløy, A., L. E. Torheim, and A. Oshaug. "Food variety-a good indicator of nutritional adequacy of the diet? A case study from an urban area in Mali, West Africa." European Journal of Clinical Nutrition 52.12 (1998): 891.

[20] Swindale, Anne, and Paula Bilinsky. "Household dietary diversity score (HDDS) for measurement of household food access: indicator guide." Washington, DC: Food and Nutrition Technical Assistance Project, Academy for Educational Development (2006).

[21] Mr. Savy. Food diversity indices: measurement and use in women of childbearing age in Burkina Faso. 06 Oct $2006 \mathrm{PhD}$ thesis. P 4522.

[22] Elodie Becquey. Validation of a food diversity indicator by the ad2quation of the diet in OUAGADOUGOU. Mémoire de fin de formation, Juil. 2006, $23 \mathrm{p}$.

[23] Cardon, Philippe. "A sociological look at the eating practices of elderly people living at home." Gerontology and society 33.3 (2010): 31-42.

[24] Action against hunger. Welding Survey on Food Diversity of Mothers and Children aged 6-59 months in three municipalities of intervention of the PADABA project. $40 \mathrm{p}$.

[25] Mathilde savy. Yves Martin Preveul. Francis Delpeuch. Measuring Dietary Diversity in Rural Burkina Faso: comparison of a one day and a tree day dietary recall. Public Health Nutrition. February 2007, 62 p.

[26] Lourme Ruiz, Alissia, Dury Sandrine, Martin-Prével Yves. Do we consume what we sow? Relationships between production diversity, agricultural income and food diversity in Burkina Faso. Cahiers Agricultures, 25 (6), 2016, 11 p.

[27] Dury, Sandrine, and Ibrahima Bocoum. "Sikasso's paradox (Mali): why isn't producing more enough to feed the children of farming families well?" Cahiers Agricultures 21.5 (2012): 324-336. 